\title{
Helping Students Reflect on Their Interpersonal Skills: The Team Performance Scale (TPS)
}

\author{
Chris Y. Lovato and Graham Shaw \\ University of British Columbia
}

\begin{abstract}
Many instructors of program evaluation incorporate team-based service projects into their courses. What is often overlooked is that it provides a golden opportunity for students to reflect on the interpersonal skills necessary for teamwork. This paper explains how we leveraged service project working groups to include reflection on interpersonal skills. Minor changes were made to the Team Performance Scale (TPS), a tool used for team-based learning in medical education. We found it to be a practical and effective way to engage students in reflecting on behaviours associated with a high functioning team. This practice note will be of interest to instructors using team learning approaches to teach key competencies in program evaluation.
\end{abstract}

Keywords: interpersonal skills, teaching evaluation

Résumé : Plusieurs formatrices et formateurs en évaluation de programme incluent des projets réalisés en équipe dans leurs cours. On oublie souvent, cependant, qu'il s'agit là d'une excellente occasion pour les étudiantes et les étudiants de réfléchir aux compétences interpersonnelles nécessaires au travail d'équipe. Le présent article explique comment nous avons tiré parti de groupes de travail sur des projets de service pour y insérer une réflexion sur les compétences interpersonnelles. Des modifications mineures ont été apportées à léchelle Team Performance Scale, un outil servant à lapprentissage par équipe dans le domaine de la formation médicale. Nous avons trouvé qu'il s'agissait d'une méthode pratique et efficace pour encourager les étudiantes et les étudiants à réfléchir aux comportements associés au bon fonctionnement d'une équipe. Cette note sur la pratique sera d'un intérêt particulier pour les formatrices et les formateurs qui utilisent des approches d'apprentissage par équipe pour enseigner des compétences clés en évaluation de programme.

Mots clés : compétences interpersonnelles, enseignement de l’évaluation

Like many others who instruct program evaluation, we have incorporated practical experiences into our course on program evaluation. For example, we use a service assignment that involves students working in small groups to develop an evaluation proposal for a real program in a government or non-government organization (LaVelle et al., 2020; Trevisan, 2004). This kind of experience represents

Corresponding author: Chris Lovato, The University of British Columbia, 317 - Health

Sciences Mall, Vancouver, BC, V6T 1Z3; chris.lovato@ubc.ca

(C) 2021 Canadian Journal of Program Evaluation / La Revue canadienne d'évaluation de programme 35.3 (Special Issue / Numéro spécial), 395-402 doi: 10.3138/cjpe.70376 
a crucial aspect of evaluation training (Gredler \& Johnson, 2001) because it offers students an opportunity to apply what they learn in the classroom to a real-world setting. Yet what is often overlooked is that it also provides a golden opportunity for students to reflect on their interpersonal skills in working effectively in a team. This paper explains how an instructor and a teaching assistant leveraged a group proposal assignment to include reflection on interpersonal skills.

\section{INTERPERSONAL SKILLS: "SOUGHT BUT NOT TAUGHT"}

Interpersonal skills are identified as a key competency area by the Canadian Evaluation Society (CES, 2018) and the American Evaluation Association (AEA, 2018). This includes a range of skills such as communication, building trust, negotiation, managing conflict, collaboration, and diversity as essential for competent evaluation practice. Although there is wide agreement regarding the need for interpersonal skills, there appears to be a discrepancy between "what is taught and what is sought." In a study examining how well the competencies students gained in graduate school matched the competencies valued by employers, interpersonal skills emerged as the area with the largest discrepancy. Employers noted the need for interpersonal skills more than any other competency, yet former students ranked interpersonal skills near the bottom in terms of the skills they gained in graduate school (Dewey et al., 2008). Galport and Azzam (2017) confirmed this gap when they found that practicing evaluators most often rated interpersonal competencies as the professional area where they most needed training.

\section{INTERPERSONAL SKILLS IN TEAM-BASED LEARNING}

While team-based learning activities have been a part of teaching for a long time, over the past decade, team-based learning (TBL) has emerged as a specific pedagogical approach to team learning for educating professionals. It is widely applied in medical education and has been used in training across the health professions, business, mathematics, and other disciplines (Betta, 2016; Dearnley et al., 2018; Haidet et al., 2014; Hanley, 2020; Peters et al., 2020). In TBL, students are placed in "permanent groups" so that they develop as a team. Students receive multiple low-stakes "readiness assessments" to ensure they grasp key concepts (typically in the form of short individual and group quizzes), and assignments require students to work collectively on application of course content (Michaelsen \& Sweet, 2008).

TBL is most appropriately used in courses where students are required to understand a significant body of information and the primary goal is to apply or use the content (Swanson et al., 2019). It is recommended as a teaching strategy for enhancing professional competencies related to interpersonal communication skills (Espey, 2018). A systematic review of TBL literature in nursing and midwifery cited number of studies that reported increasing interpersonal skills as an outcome of TBL (Dearnley et al., 2018), and similar findings have been reported in medical education (Zgheib et al., 2016). 


\section{TEACHING CONTEXT}

We teach a graduate-level course called "Program Planning and Evaluation." The course is an elective in the Masters of Public Health (MPH) program, in the School of Population and Public Health, University of British Columbia. The course prerequisites are epidemiology and statistics. There are typically 30 students enrolled in the course. Students receive instruction on program evaluation both in the classroom and online (via Canvas) over a 13-week period. Topics include program planning models, planning and designing processes, communicating and reporting of results, and managing an evaluation.

We assigned students to small work teams (four to five students each) during the second week of the course. Similar to TBL, the teams were organized to maximize diversity within groups while still maintaining a balance of experience and research skill across groups (e.g., $\mathrm{PhD}$ students were dispersed across groups). Unlike TBL, this course did not involve the use of readiness assessments to test knowledge. As with TBL, groups worked together on weekly activities requiring application of concepts, including a service project worth $30 \%$ of the final grade. The service project required teams to apply course content by developing an evaluation proposal for a public health program currently being planned or implemented.

The primary instructor works with government and non-government agencies to arrange for these placements. Community organizations identify a program that they would like to have evaluated, and the students develop an evaluation proposal over a five- to six-week period. The agency is asked to provide a sponsor who meets with the group at least three times: (1) at the beginning to explain their needs, (2) a few weeks later to discuss the general approach students have identified, and (3) at the end of the term to receive a presentation and a copy of the final proposal. These meetings typically last one hour. Student groups identify one member who handles all communication with the sponsor. The instructor is copied on all student communication.

\section{THE TEAM PERFORMANCE SCALE}

To facilitate individual and group reflection on the effectiveness of students working in teams, Thompson et al. (2009) developed a tool called the Team Performance Scale (TPS) for use in medical education courses. The TPS is a student self-report instrument that focuses on levels of engagement by all team members, processes for inviting deep conceptual discussion that respect and value diverse perspectives, and the strength of team identity and commitment. The 18-item survey is open access and can be found in Thompson et al.

The item response scale ranges from "none of the time" (scored 0 ) to "all of the time" (scored 6). The creators of the scale first developed a set of 30 items based on a literature review of characteristics of high-functioning teams. Through a process of psychometric testing and validation with students from multiple medical schools, they used factor analysis to reduce the instrument to 18 items 
that fit into a single factor structure with high internal consistency (Cronbach's alpha $=0.97$. Examples of stems include "When team members had different opinions, each member explained his or her point of view; my team elicited multiple points of view before deciding on a final answer; my team used several techniques for problem solving (such as brainstorming) with each team member presenting his or her best ideas." We made minor editorial changes to the survey and used the TPS to help facilitate student teamwork. While our course was not designed as a complete TBL course, permanent diverse teams were formed to work on a real-world application project, suggesting that the TPS would add an important aspect to students' learning.

To incorporate the survey into our teaching, we gave an in-class lecture about the concept of team service projects, behaviours associated with effective teams, and how the team proposal assignment addressed key evaluation competencies. The need to take time to reflect on group processes was emphasized and tensions within work teams were described as a normal occurrence that can be positive and productive.

Approximately two weeks after student teams began working on their evaluation service projects, the TPS was introduced and students were asked to fill them out individually, in class. Class time was then provided for students to compare and discuss responses in teams within the privacy of their own work group. Scores were not compared between teams or collected as data. Teams were encouraged to discuss results and identify areas where the instrument suggested that work would lead to improved team function. The instructors made themselves available for questions or consultation. The primary instructor observed the group interactions from the front of the classroom and intervened if support appeared to be needed.

\section{INSTRUCTOR'S REFLECTIONS}

As an experienced professor, I have been incorporating group service projects into my courses for many years. Students consistently expressed very positive sentiments about those projects. Their feedback indicated that they view this activity as one of the most important experiences in their program. Complaints, when received, were most often about unequal contribution of team members. I also heard some grumbles about "getting things done" and inefficient group processes.

While "interpersonal skills" and "working collaboratively" are stipulated as key competencies, as a teacher of evaluation I recognized that I had been lax in defining behavioural indicators of those competencies. Some, but not all, of my students have work/life experience that has taught them those skills and some have more developed skills than others. I was interested in integrating a low-stakes, non-intimidating activity into my course that facilitated reflection and development of interpersonal skills necessary for evaluation practice and strengthened students' ability to successfully complete a team assignment. 
In searching the literature for something that would help me articulate the behaviours associated with healthy work-team functioning in a post-secondary setting, I ran across the Team Performance Scale (TPS). I chose to use this instrument because it is based on research about high-functioning teams, it has favourable psychometric properties (i.e., construct validity and reliability), it was developed specifically for university students, and it is simple and quick to administer.

Thus far, I have used the TPS as a way to specify key behaviours that relate to good team functioning, engage students in reflecting on their individual performance, and engage work groups in reflecting on performance as a group. The TPS allows students to identify those areas in which they need to improve in order to function well in completing their project.

Students report that they find the TPS exercise engaging and valuable. It seems to refresh or enhance their understanding of what it takes to develop a healthy and effective working group. It also provides a framework for a structured conversation that focuses on specific expectations and accountabilities. I have observed that they are highly engaged and take up the challenge of reflecting openly about how their different contributions and perspectives can lead to a better team outcome. As one student stated, "I have been in many classes in university that required group work, but this is the first class I have taken that has a focus on team building and working together to bring out people's strengths."

I have found that a team-based service project provides opportunities to incorporate instruction and practice on working in a group and gives students the real-world experience of working collaboratively. The items specify feasible behaviours for a work group. The TPS helped me to specify what behaviours lead to working successfully in a team.

\section{TA'S REFLECTIONS}

I have enjoyed using the TPS as a tool to promote discussion and reflection among student groups. I find that this approach engages students and makes the discussion with peers meaningful. It focuses discussion on the real and present experience of a shared project and engages their emotions by drawing attention to how they are being perceived by their peers. While the ultimate aim is to build teamwork skills for later program evaluation work, the application in an assignment provokes explicit questioning around the strengths of team members and how they each contribute.

Not infrequently, there is a group that fails to perform on a group task. Members of the group can enter a non-productive cycle of blaming one member or each other. I believe that presenting interpersonal skills as a necessary skill in evaluation and using the TPS to highlight some potential problems makes it clear to students that we expect them to deal with the interpersonal challenges inherent in group work. In previous courses, we presented excellent material about working in groups, but students did not seem to connect with the material in the way they did using the TPS. 


\section{CONCLUSION}

The TPS is a practical and effective way to engage students in reflecting on the specific behaviours associated with a high-functioning team. We have found that students are open and receptive to using the survey and find it useful. One of the limitations of the way in which we structured this exercise was that we did not include a facilitated discussion to get at the heart of the process; nor did we facilitate group conversations about assumptions that teammates often make about themselves and others. There may be unintended negative effects of leaving the discussion as private to their group. A second limitation is that we do not know the extent to which the TPS self-reported behaviours reflect actual behaviour. Nevertheless, in a teaching setting, the instrument provides students an opportunity for reflection, awareness, and accountability for interpersonal behaviours that are critical to successful evaluation practice.

In the future, we plan to explore these and other possible issues by conducting a focus group post-assignment to gather more specific feedback on how this activity can be improved to meet student needs. We also want to do further work to explore what issues came up most frequently, where students feel stuck, and what might be done to assist them in moving forward. A cautionary note about teambased projects: There remain down sides to teamwork and some students simply don't like it. Balancing team assignments with other individual assignments can help address this issue.

In conclusion, interpersonal skills have been identified as a key competency for evaluators. Despite their critical role in professional practice, these skills are rarely addressed in graduate training programs. There are a range of approaches and strategies used to teach evaluation (King \& Ayoo, 2020). Many evaluation courses involve team-based learning, either by course design or through team activities. These approaches provide an ideal opportunity for students to learn about, practice, and reflect upon the skills needed to be part of an effective evaluation team. We have found the TPS to be a practical and effective tool to facilitate students' learning in this important competency area.

\section{REFERENCES}

American Evaluation Association (AEA). (2018). AEA evaluator competencies. https:// www.eval.org/page/competencies

Betta, M. (2016). Self and others in team-based learning: Acquiring teamwork skills for business. Journal of Education for Business, 91(2), 69-74. https://doi.org/10.1080/08 832323.2015.1122562

Canadian Evaluation Society. (2018). Competencies for Canadian evaluation practice. https:// evaluationcanada.ca/txt/2_competencies_cdn_evaluation_practice.pdf

Dearnley, C., Rhodes, C., Roberts, P., Williams, P., \& Prenton, S. (2018). Team based learning in nursing and midwifery higher education: A systematic review of the 
evidence for change. Nurse Education Today, 60, 75-83. https://doi.org/10.1016/j. nedt.2017.09.012

Dewey, J. D., Montrosse, B. E., Schröter, D. C., Sullins, C. D., \& Mattox, J. R. (2008). Evaluator competencies: What's taught versus what's sought. American Journal of Evaluation, 29(3), 268-287. https://doi.org/10.1177/1098214008321152

Espey, M. (2018). Enhancing critical thinking using team-based learning. Higher Education Research \& Development, 37(1), 15-29. https://doi.org/10.1080/07294360.2017. 1344196

Galport, N., \& Azzam, T. (2017). Evaluator training needs and competencies: A gap analysis. American Journal of Evaluation, 38(1), 80-100. https://doi.org/10.1177/109 8214016643183

Gredler, M. E., \& Johnson, R. L. (2001). Lessons learned from the directed evaluation experience. American Journal of Evaluation, 22(1), 97-104. https://doi.org/10.1016/ s1098-2140(01)00115-1

Haidet, P., Kubitz, K., \& McCormack, W. T. (2014). Analysis of the team-based learning literature: TBL comes of age. Journal on Excellence in College Teaching, 25(3-4), 303. https://www.ncbi.nlm.nih.gov/pmc/articles/PMC4643940/

Hanley, J. (2020). Team-based learning in social work law education: A practitioner enquiry. Social Work Education, 1-13. https://doi.org/10.1080/02615479.2020.1770720

King, J. A., \& Ayoo, S. (2020). What do we know about evaluator education? A review of peer-reviewed publications (1978-2018). Evaluation and Program Planning, 79, 101785. https://doi.org/10.1016/j.evalprogplan.2020.101785

LaVelle, J. M., Lovato, C., \& Stephenson, C. L. (2020). Pedagogical considerations for the teaching of evaluation. Evaluation and Program Planning, 79, 101786. https://doi. org/10.1016/j.evalprogplan.2020.101786

Michaelsen, L. K., \& Sweet, M. (2008). The essential elements of team-based learning. New Directions for Teaching and Learning, 116, 7-27. https://doi.org/10.1002/tl.330

Peters, T., Johnston, E., Bolles, H., Ogilvie, C., Knaub, A., \& Holme, T. (2020). Benefits to students of team-based learning in large enrollment calculus. PRIMUS, 30(2), 211-229. https://doi.org/10.1080/10511970.2018.1542417

Swanson, E., McCulley, L. V., Osman, D. J., Scammacca Lewis, N., \& Solis, M. (2019). The effect of team-based learning on content knowledge: A meta-analysis. Active Learning in Higher Education, 20(1), 39-50. https://doi.org/10.1177/1469787417731201

Thompson, B. M., Levine, R. E., Kennedy, F., Naik, A. D., Foldes, C. A., Coverdale, J. H., Kelly, P. A., Parmelee, D., Richards, B. F., \& Haidet, P. (2009). Evaluating the quality of learning-team processes in medical education: development and validation of a new measure. Academic Medicine, 84(10), S124-S127. https://doi.org/10.1097/ acm.0b013e3181b38b7a

Trevisan, M. S. (2004). Practical training in evaluation: A review of the literature. American Journal of Evaluation, 25(2), 255-272. https://doi.org/10.1177/109821400402500212

Zgheib, N. K., Dimassi, Z., Bou Akl, I., Badr, K. F., \& Sabra, R. (2016). The long-term impact of team-based learning on medical students' team performance scores and on their peer evaluation scores. Medical Teacher, 38(10), 1017-1024. https://doi.org/10.3109/ 0142159x.2016.1147537 


\section{AUTHOR INFORMATION}

Chris Y. Lovato is a professor at the School of Population and Public Health at The University of British Columbia, where she teaches and conducts evaluation research. Her academic career has focused on conducting applied health research that informs decision making through evaluation studies. Her research has examined the effectiveness of school health, college health, health services, community health, and medical education.

Graham Shaw is a doctoral candidate at the School of Population and Public Health at The University of British Columbia, where he has served as a teaching assistant and instructor. His research is focused on context-informed knowledge translation to improve population health. 